

\title{
INTERPLAY BETWEEN SUBSTANCE USE AND HEALTH: BEHAVIOURAL DYNAMICS AMONG FEMALE ADOLESCENTS IN BUTTERWORTH, SOUTH AFRICA
}

\author{
Samkelo Bala, Simon Kang'ethe \\ Mr Samkelo Bala, Postgraduate Student, Department of Social Work/Social Development, University \\ of Fort Hare, South Africa.
}

Professor Simon M. Kang'ethe, Department of Social Work/Social Development, University of Fort Hare, South Africa.

\section{INTRODUCTION}

The phenomenon of substance abuse, especially among youths, is one of the leading problems confronting South Africa today. The prevalence of alcohol and drug abuse has in the recent years taken an unrelenting upwards curve. Taking the consumption of alcohol as an example, current statistics indicate that the country consumes 5 billion litres of alcohol a year, which contributes massively to the carnage on the roads, as well as crime and foetal disorders (Pedersen, 2016). This high rate of substance consumption and business dealings means that the country has earned the title of a drug mecca of the world (Geyer \& Lombard, 2014). Substance abuse among adolescents in South Africa has become a major dilemma and a cancer that destroys their lives (Peltzer \& Phaswana-Mafuya, 2018). Sadly, South African adolescents have associated the consumption of substances with pleasure and relief. Female adolescents are taking as many substances as their male counterparts and this is becoming a major problem facing South Africa. The consumption of drugs and alcohol has taken a huge toll on community values and standards. The literature highlights that female adolescents use methamphetamine drugs as much as males do (Dada, Burnhams, Laubscher, Parry, \& Myers, 2018).

Kang'ethe and Nomngcoyia (2014) contend that most illicit behaviours in South Africa are driven by an excessive intake of alcohol and drugs. This is because these substances makes the users prone to perform an array of hazardous behaviours, especially of a sexual nature (Groenewald, Essack \& Khumalo, 2018). The literature further highlights that when adolescents are under the influence of these substances, they are less likely to take precautions such as considering the use condoms, for example (Groenewald et al., 2018). Findings also indicate that when female adolescents are under the influence of drugs and alcohol, they became prey to the sexual activities of older men (Khuzwayo \& Taylor, 2018). Kang'ethe and Rhakudu (2010) corroborate these findings and contend that it is no longer uncommon for those under the influence of alcohol to engage in multiple sexual activities with different partners, usually without any precautions against diseases such as HIV/AIDS. Therefore, there is much evidence linking substance abuse among adolescents to innumerable unhealthy behaviours.

Perhaps what is worrying in countries such as South Africa is the normalisation of taking such substances even by younger people without fearing the presence of the adults (Jelsma \& Armenta, 2015). This is happening because of an apparently new culture of allowing children to carry and drink alcohol in public spaces (Bala, 2017). This no longer makes adults raise eyebrows. This means that the cultural and moral goal posts are changing, with the normalisation of most behaviours that in the past were considered taboo (Nwagu, 2016). It is therefore critical that society's definition of morality and immorality are subjected to a new critical analysis. But whatever society wants to condone, it is still necessary to indicate that most societies benchmark their morality with what is culturally upheld as morally acceptable as well as with what the sacred writing of most religions of the world hold. However, there is always some subjectivity and therefore societies need to come up with their own ideas of what they would consider to constitute moral or immoral behaviour (Kang'ethe \& Rhakudu, 2010). 
There is a need to point that South African societies' moral compass started failing them when they succumbed to the forces of Westernization and Eurocentrism, which had the effect of relegating their cultures to a second place compared to the cultures of the Western countries (Van Zyl, 2013). In support of the above, findings by Negm and Fouad (2014) contend that in Western culture experimentation with substances and partying by adolescents is considered to be a developmental normative behaviour. Therefore, the culture of an excessive consumption of alcohol has been an imitation of the Western-centric way of life, with Africans tending to overdo the habit (Goliath \& Pretorius, 2016). This has complicated the dynamics of the country's ethical behaviour. It has prevented the country from going back to following most traditional cultural dictates, just like Japan, which has clung to its traditional culture in tandem with development (Arowolo, 2016). In the same vein, many moral and cultural architects think that embracing traditional moral and cultural values could possibly lead to a moral turnaround and moderate most people's behaviours (Nomngcoyiya, 2018). It should no longer be tenable to think that one has to throw away one's own culture in order to make way for development, modernisation or globalisation (Brecht \& Herbeck, 2013). The impacts of substance abuse have been detestable, detrimental, shocking and immensely painful. This is because there is an inextricable relationship between substance abuse and the prevalence of crime in the country (Mothibi, 2014). With the country experiencing the highest cases of various kinds of crime, the high rate of substance abuse needs to be addressed. It also needs to be borne in mind that the high crime rate has a negative impact on foreign direct investment, as potential investors prefer to invest their resources in more tranquil and secure environments bereft of crime. This is a serious blow, considering that the country is experiencing one of the lowest growth rates in the world, especially after being consigned to junk status by the ratings agencies (Mothibi, 2014). This paper, therefore, is an attempt to stimulate debate on the interplay between substance abuse among the female adolescents and behavioural changes. Furthermore, the paper gives hope that interventions that would bridge the gender divide would be a sure way of addressing the substance consumption behaviour among female adolescents. Dada, Burnhams, Laubscher, Parry and Myers (2018) point out that the literature highlighting substance abuse among female adolescents is scanty.

\section{METHODS AND STUDY SETTINGS}

The goal of this study is to examine the interplay between substance abuse behaviours among adolescents and youths generally and their consequent behaviours. The paper will also create an educational platform to educate female adolescents and their parents on the ramifications associated with substance abuse.

\section{Research approach and design}

This study utilised a qualitative paradigm and used a case study design. The qualitative paradigm entailed the paradigmatic ethos of subjectivity, induction, value-ladenness, the researcher being close to the participants and, rhetorically, the principal researcher using the first-person to record participants' insights (Creswell, 2014). The study also utilised qualitative approach, meaning that the study was explorative and descriptive in nature, since not much has been documented on drug-abuse habits among female adolescents in the rural areas of the Butterworth region (Babbie, 2014). The qualitative research design allowed the gathering of views, thinking, insights and attitudes of female adolescents as well as other stakeholders on the dynamics of substance abuse by female adolescents from Mission Location. The research design is an exploratory case study in that only a few samples were used in order to generate massive in-depth data to help to answer the study's research questions (Creswell, 2014).

\section{Populations and sampling}

The population of this study was drawn from Butterworth in Eastern Cape, South Africa. Specifically, the population involved female adolescents and former users of substances, parents of the female adolescents using substances, as well as the following key informants: social workers, probation officers, community leader, teachers, and the South African Police Service (SAPS). Furthermore, a purposive sampling technique of non-probability sampling has been utilised to select population with 
characteristics that concerns the study (Babbie, 2014). Through applying the above technique, 26 participants were selected. Participants were asked the following questions: What are the immoral behaviours associated with substance abuse among female adolescents at Butterworth, Eastern Cape? What are the sexual risk behaviours associated with substance abuse among female adolescents at Butterworth Eastern Cape? What kind of violence is associated with substance abuse among female adolescents at Butterworth, Eastern Cape? How does substance abuse among female adolescents influence their academic progress in Mission Location at Butterworth, Eastern Cape? The data were verified through peer reviewing and comparing data from individual responses, group responses and key informants. Notes kept during the data-collection process were also referenced.

\section{Data collection}

Data collection was cross-sectional in that it was collected within a short time span; methods used were focus group discussions, one-on-one interviews and discussions with key informants (Rubin \& Babbie, 2015). Focus groups and one-on-one interviews with 26 participants were conducted to allow participants to express their views from their own perspectives in their own languages (Creswell, 2014). The study data collection was approved by the Ethical Committee of the University of Fort Hare. The researcher also requested permission from parents and schools to collect data from adolescents. The Department of Basic Education provided permission for the researcher to conduct the study.

\section{Research instrument}

An interview guide with structured question was used to guide both one-on-one interviews and the focus groups discussions. The interview guide helps the researcher to direct the conversation towards the topic and investigate the issues which the research seeks to explore (Rimando, Brace, NamageyoFuna, Parr, Sealy, Davis, Martinez \& Christiana, 2015).

\section{Sampling methods and techniques}

This study used a non-probability sampling methodology. This allows the researchers to pick the samples based on their interests and intuition that the selected participants would appropriately answer the study's research questions. The researcher specifically utilised a purposive technique. The strategy, therefore, allowed the sample selection of the participants who were assumed to be data-rich and able to offer useful manifestations of the phenomenon under study (Maxfield \& Babbie, 2015).

\section{Sample selection criteria}

This study applied a sample selection criterion of inclusion and exclusion. Therefore, this study recruited 26 participants through purposive sampling; 7 female adolescents using substances or former casualties of substance abuse residing in Mission Location of Mnquma Municipality were included. In this study the term 'female adolescents' has been operationalised to mean any female between the age of 10 to 19 years. They included 9 parents with children using or who have used alcohol and drugs; 1 community leader; 3 social workers, 2 teachers; 2 probation officers and 2 police officers were included. The study therefore excluded parents who had no female children abusing substances, female adolescents who were not taking substances, or those who never had the history of using substances. It also excluded the teachers, social workers and police officers who were not serving at Mission location.

\section{Data analysis}

The study adopted qualitative data analysis, therefore the data were analysed in the form of thematic analysis. Data analysis is the process of bringing order, structure and meaning to the mass of collected data through explanations and interpretations (De Vos, Strydom, Fouché \& Delport, 2005). Thematic analysis was utilised to identify fundamental patterns that address the phenomenon being studied. Specifically, latent thematic analysis was used, so as to look beyond what the participants gave. Braun and Clarke's six steps were used as guidance to formulate themes. The researcher familiarised himself with the collected data through listening to audio recordings and transcribing the material. 


\section{Research domain justification}

The study was done in Mission Location of Mnquma Municipality of Eastern Cape. The area is $100 \%$ inhabited by Xhosa-speaking people who observe the same cultural practices. The area is also povertystricken. The researcher observed that young people, particularly female adolescents, were increasingly using substances.

\section{Ethical consideration}

To protect the human dignity of the participants, the researcher adhered strictly to the ethical guides and principles. The researcher requested informed consent from parents, schools and participants. This is because ethically it is necessary that participation must be voluntary (Rubin \& Babbie, 2010). To maintain privacy, anonymity and confidentiality, the researcher assured the participants that the information they gave was only for research and it was not accessible to any other individual, other than the information being used to write journals. The researcher additionally ensured that participants' identity was withheld. The researcher also ensured that the meeting venue was private. To ensure anonymity, the researcher did not collect identifying personal details of the participants, like their real names and addresses. Code names were given and just the researcher knew who was connected to which code name (Creswell \& Plano Clark, 2011). Female adolescents under the age of 18 years and their parents were provided with informed consent forms. The research tool (interview guide) for data collection was reviewed and endorsed by the Ethics Committee of the University of Fort Hare. The Department of Basic Education Eastern Cape, the School Governing Body and School Principal gave permission to collect the data.

\section{FINDINGS OF THE STUDY}

\section{Demographic details of the participants}

A total of 26 people residing at Butterworth town in the Eastern Cape were interviewed to collect data, with seven (7) female adolescents, nine (9) parents and community members. Subsequently 10 key informants were included in the study, specifically two (2) police officers, two (2) probation officers, two (2) educators, three (3) social workers and one (1) community leader. Female adolescents and parents were interviewed individually and in separate focus groups. The key informants were also interviewed individually. The participants were accessed through community leaders, the Butterworth Department of Education office and the School Principal.

Age

The female adolescents' ages ranged from 15 to 19 years. This means that the study achieved data trustworthiness and credibility, as all the females investigated were adolescents. The study was gender skewed in the sense that only the views, insights, attitudes and practices of the female adolescents were solicited.

The ages of the parents who took part in the study ranged from 50 to 63 years. Given that all the targeted parents availed themselves of this opportunity, it is evident that they were concerned about substance abuse in Mission location. However, the age of the parents may be a drawback in substance abuse prevention as most parents - perhaps because of their advancing age - may not have been motivated to bother much about their adolescent children's development; or they may no longer have a strong control of their children's discipline, with the result that the adolescents took advantage of that freedom and neglect to abuse substances. There were 10 key informants who ranged from the age of 35 to 60 years.

\section{Marital status}

Four parents were widowed, four were single, three had never married, one parent was divorced, and one parent was married. Since the majority of the parents were single, this environment could be influencing the substance abuse behaviour among adolescents. The above findings are supported by Jackson, Rogers and Sartor (2016), who posit that single parenting and divorce have shown an 
escalation in vulnerability to substance use among adolescents. Four of key informants were single, 5 married and 1 was widowed.

\section{Education}

Three adolescents had dropped out of school before reaching Grade 12, while four adolescents were having difficulties progressing in Grade 9 and Grade 10. Findings by Tshitangano and Tosin (2016) corroborate this study's findings that substance use has derailed and affected learners' academic performance. The findings of this study illustrated that one parent was a professional teacher and another one a police officer. Seven parents never attained Grade 12; three of them had reached Grade 11 and four had reached Grade 9. The low levels of literacy may explain the higher levels of unemployment and poverty in the area. In fact, most of the parents were unemployed and relying on social grants. Because of the apartheid demographic segregation that pushed blacks to live in isolated areas, Mission Location is dominated by black people, specifically Xhosa people.

Two of the key informants were police officers, one with a degree qualification, while the other had a diploma. Furthermore, both probation officers, the three social workers and the two teachers had degree qualifications. The community leader was a retired teacher. Since all the key informant participants who the researcher targeted availed themselves of the opportunity, this mirrors the readiness of the Mission community to face the challenge. It may also indicate that incidents of substance abuse among adolescents at Mission Location had been reported to different government departments.

\section{Main themes}

The findings of the study resulted in the following main themes.

\section{Substances consumption among female adolescents motivates sexual behaviour in public places}

This study revealed that excessive substance consumption among female adolescents made them prone to engage in sexual activities in public places. Such behaviours included kissing in public places, and even engaging in sexual intercourse in school toilets and on the school premises generally. This triggered protests from their parents and community members. The following comments support the finding:

I saw two children kissing each other next to where the community wait for transport. (Parent)

Yesterday, I practically saw children having sex in school toilets after school. (Principal)

Few days back, when I was patrolling the area with my colleagues, young girls were having sex with two boys next to FNB. (Probation officer)

It is a shame our children are sexually active. They even practise sexual intercourse in daylights. (Social worker)

It is not uncommon these days to see many adolescents having sexual intercourse in dark corners around the town. (Police)

It is very shocking to see young children in town in public having sexual intercourse in public. (Social worker)

Drugs have caused shame in our communities; children are disobeying community values. (Community leader)

The above views corroborate the ethical behavioural changes manifested by the school adolescents engaging in sexually irresponsible behaviours. This also points to the way that excessive use of substances can negatively influence the adolescents' behaviours. This may also indicate the state of moral decadence the community is experiencing. These findings suggest that the adolescents were following the footsteps of the adults who are slightly older than them; or society seems to tolerate their behaviour. 


\section{Female adolescents' sexual engagement driven by pecuniary goals}

Most of the research participants in this study indicated that substance consumption made adolescents to engage sexually with many partners for pecuniary reasons. This prompted many parents to lament the moral degeneration of their children. The elders were also at a loss for words upon realising that their adolescent children were engaging in multiple sexual endeavours, especially for alcohol in exchange. Female participants indicated they were often partying during the weekends, where they would meet those who could buy them beer or offer other rewards. The following verbatim sentiments were expressed by the participants:

"When I was drinking, I never used my money to buy alcohol. I used to get free booze in exchange for sex with whoever would buy me alcohol." Female adolescent.

"Age is just a number. As long as someone would buy me and my friends' expensive alcohol, I would not mind to pay back through sex." Female adolescent.

"My child used to go out every weekend and come home drunk, but she was not working." Police.

"I took advantage of being a girl to be bought all the alcohol I needed. Of course, the buyer would demand sex and I would agree to the request without any coercion." Female adolescent.

The above findings suggest the culture that the female adolescents had sunk into of freely using their sexual powers for free alcohol. This also indicates the risks they face of contracting sexually transmitted diseases. This further shows that there are poor primary interventions to deal with substance abuse, especially at schools. The above sentiments suggest a likelihood that adolescents are not likely to do well in their school work. The scenario also suggests an increased likelihood of higher rates of teenage pregnancy, fatherless children and the high risk of contracting HIV.

More than half of the participants indicated that female adolescents, due to their lifstyles, were at a high risk of contracting HIV and other infectious diseases. This was because of their behaviour of sleeping around carelessly with whoever would buy them alcohol. The following sentiments support the finding:

I don't think they even use condoms because they sleep with different partners carelessly. (Parent)

In most cases, since they sleep with older people, sometimes they don't have much decision in using condoms. (Police)

It is very rare to use a condom when both partners are drunk. (Female adolescent)

The above sentiments not only suggest the dangers that the adolescent girls face of heightened chances of contracting HIV and other sexually transmitted diseases, but also suggests the challenges that intergenerational sex poses to the HIV/AIDS campaign. The sentiments also point to the role of poverty in possibly driving states of moral decadence and higher rates of HIV/AIDS. This is also confirms an inextricable relationship between poverty and escalation of HIV/AIDS. The scenario may also point to a lower level of awareness of substance and HIV/AIDS in the region.

\section{Female adolescents normalised the abuse of alcohol in public places}

Virtually all the research participants confirmed that substance consumption prompted most adolescent females to normalise public drinking to an extent that some students went to school smelling of alcohol and dagga. The behaviour also prompted truancy and made them disobedient to their teachers. The following sentiments were made by various participants:

The adolescents have lost morals. They come to school even if they are drunk. (Teacher) 
As parents, it is painful to see many of our young children drinking in public places. It is also a shame not only to the children, but also to a host of us parents. Something has absolutely gone amiss in families. (Parent)

Our community has turned out to be a laughing stock. Our children don't obey community ethics and principle. (Community leader)

The above findings indicate how the Mission Location youths have embraced acts of immorality due to a culture of substance consumption. The findings also indicate that parents and the whole society may also be failing in nurturing their children to be responsible and morally upright. Apparently the African tradition that a child should be raised by the whole community has increasingly been failing to inculcate its values and norms. This should sends a message to the government to consider launching strong substance abuse awareness interventions, if the youths of the Mission Location are ever going to be good and productive citizens.

\section{Substance consumption creates a fertile ground for conflict}

The study findings revealed that the use of drugs compromises the state of peace and tranquillity among one's friends, community friends and significant others. This means the substance abuse among the adolescents is creating conflicts among family members. This is because substance users cannot be trusted even by their own family. This is probably because the substance users ask for money to buy the drugs and sometimes steal money in order to satisfy their addictive habits. Furthermore, the guardians of the adolescents have to be called to the school frequently because of the wrongs committed by their children.

The following quotes express the views of participants:

She is loathed by her siblings because of her pilferage nature. She steals everything at home. (Parent)

I am always called to go to school by the principal because of her behaviour. (Parent)

My grandchildren's behaviour have caused me to engage in endless conflicts in this community. It is an awful thing to engage in substances. (Parent)

The researcher thinks that the culture of substance abuse could largely be contributing to the South African culture of crime and violence, and community conflicts. The above findings should challenge the government to monitor access to substances among the adolescents through fully engaging with different stakeholders, including non-governmental organisations. It would be important if the environment of the drug-taking culture is dealt with rather than waiting to react to the aftermath of the substance abuse culture.

\section{DISCUSSIONS OF THE FINDINGS}

The findings of this study revealed a state of gender imbalance, as there were a larger number of female parents than male parents. This agrees with Montgomery and Marinos (2016) that male parents are always less involved and oblivious to their children's development and the monitoring of their interactions. It is therefore essential that government considers introducing affirmative programmes that will recruit and teach male parents about the importance of their involvement in their children's development. The findings also indicated that there were more families headed by widows and single parents, which registers an environment of possibly less control and lowered capacity to discipline their children, which is an environment offering fertile ground for adolescent involvement in substance abuse. This scenario is confirmed by Smith and Estefan (2014), who contend that the increasing rate of divorce in the country has resulted in many single-parent families. The situation has ramifications of a changing family landscape, which could in turn contribute to various practices indicative of moral decadence. 
Study findings also revealed that a large number of female adolescents who were using substances were school dropouts and many others were struggling to pass their grades. These findings seem to agree with those researchers who recognise that the problem of substance abuse among the adolescents has a negative influence on the discipline and performance of the students, and the phenomenon has aggravated the rate of school dropouts (Simatwa, Odhong, Juma \& Choka, 2014; Tshitangano \& Tosin, 2016). Substances abuse among female adolescent has been regarded as a cancer that has eaten deep into the fabric of the educational environment and has caused many setbacks for secondary school and tertiary-level female adolescent students in their pursuit of an education (Maithya, Okinda \& Mung'atu, 2015). Substance abuse erodes the necessary learning motivation and leads to poor academic performance (Chesang, 2013). Students should constantly be discouraged from using substances and be educated about their dangers. Based on the findings of the United Nations Office on Drugs and Crime (2017), drug and alcohol consumption may, for instance, be responsible for shifting individuals' resources away from schooling because they suffering from an impairment of short-term memory and other intellectual faculties, impairment of tracking ability in sensory and perceptual functions, and generally impaired classroom performance. More importantly, reduced cognitive efficiency leads to weak academic aspirations, resulting in a decline in self-esteem and the adolescent may eventually drop out of school altogether (Nadenge, Muasya, Mukhungulu, Mwangi, Ewoi \& Gabriel, 2016). Adolescents who abuse drugs may undermine and neglect their schoolwork making them less likely to attend classes or keep up within their studies and are less likely to value academic achievements; they expect less academic success and do in fact obtain lower grades (Mudavanhu \& Schenck, 2014).

This study revealed that the impact of excessive indulgence in drugs among the female adolescents made them prone to engage in risky sexual engagements in public places. A study by Van Zyl (2013) shows that substance abuse among adolescents involves bad sexual decisions, making them prone to disregard social norms and community rules and to have sex in public spaces during the day. There is an inextricable link between substance abuse and sexual misconduct among the female adolescents, with adolescents even daring to have sex in school public toilets (Bala, 2017).

The findings of this study indicate that substance abuse among female adolescents has resulted in behaviour such as kissing in public places. For instance, the research conducted by Mohasoa (2010) shows that the consequences of substance abuse amongst South African youths include disrespectful sexual relations, which put them at risk of contracting STIs and HIV/AIDS. However, most research on substance abuse has proven that people using substance develop impaired moral reasoning in that many even perform sexual activities in public shelters and in derelict houses (Maponyane, 2012).

Findings suggested that female adolescents were engaging in sexuality for pecuniary gains. This is because they were usually sleeping with financially stable or working men to get money for alcohol. Meade, Watt, Sikkema, Deng, Ranby, Skinner, Pieterse and Kalichmann (2012) seem to agree with these findings that female adolescents were sleeping with working men in exchange for expensive substances, while others would sleep with drug sellers in order to get free drugs. Kheswa and Mahlalela (2014) confirm that sexual promiscuity among female adolescents also occurs because of a drugfriendly atmosphere. Thus, there is also a high risk of teenage pregnancy. Currently, female adolescents are trading with sex for expensive substances, more specifically those who are in institutions of higher learning (Mokwena \& Fernandes, 2014).

The findings also indicated that female adolescents were at a higher risk of contracting HIV and other infectious diseases because of their lifestyles. This was because of the behaviour of sleeping out carelessly with whoever would buy them alcohol. There is a much evidence which indicates that female adolescents had sexual encounters after using substances and more likely to have unsafe sex (Ritchwood, Ford, DeCoster, Sutton \& Lochman, 2016). This is also supported by Woods-Jaeger, Jaeger, Donenberg and Wilson (2013) that substance abuse among adolescents is linked with a multiplicity of risky sexual behaviours and sexually transmitted diseases (STIs) because of inconsistent condom use and multiple sexual partners. Substance abuse among adolescents has increased the likelihood of acquiring STIs and HIV, because they neglect condom use (Asante, Meyer-Weitz \&

Social Work/Maatskaplike Werk 2020:56(4) 
Petersen, 2014). Parents also have a pivotal role of ensuring they admonish their children while they are still young. Substances like methamphetamine use increase libido and impulsivity and decreased restraint, which may prompt unsafe sexual conduct and make people vulnerable to HIV and other sexually transmitted diseases (Meade, Watt, Kimani, MacFarlane, Choic, Skinna, Pieterse, Kalichman \& Sikkemaa, 2014). When university female adolescents are dependent on substances, they may also take to prostitution as means of making easy money to sustain their drug-taking habits (Asante, et al., 2014). A study conducted by Bala (2017) found that substance abuse contributes greatly to risky sexual behavioural practices both because of the increased sexual vitality while high, but also the routine of trading sex for the substances. When females have consumed the drugs, they become high, make wrong sex-oriented judgements and become engage sexually with as many individuals as possible, whom they would not accept if they were not under the influence what can this mean?

(Asante, et al., 2014; Mogotsi, Nel, Basson \& Tebele, 2014). Their condition does not allow an opportunity for negotiating for safer sexual practices. It is necessary to note the mythical belief held by the majority of female adolescents that consuming alcohol before sex motivates their sexual drive, increases and heightens their enjoyment or improves their sexual performance and hence they are even able to sleep with two or more partners in one night (Osman, Victor, Abdulmoneim, Mohammed, Abdalla, Ahmed, Ali \& Mohammed, 2016).

The findings indicated that substance consumption prompted most adolescent females to normalise public drinking to the extent that some students went to school smelling alcohol and dagga. Nyabadza and Hove-Musekwa (2010) agrees that public drinking among the youth has been viewed as a kind of freedom, since many were found carrying substances, especially alcohol, and walking around drunk during the day. This should alert the government that serious education on substance abuse is needed and that enforcing the policy against selling of substances to adolescents is essential.

The study findings suggested that the use of drugs compromises the state of peace and tranquillity with one's friends, community friends and significant others; people who are dependent on drugs are dangerous and capable of doing something immoral to get drugs when they are craving to use them. Kang'ethe and Nomngcoyiya (2014) found that drug victims have been robbing HIV/AIDS facilities to get ARVs in order to make nyaope and drug-dependent users have been mugging ARV patients to make the drug locally for themselves. This means the community is not safe anymore. Substance abuse is a very expensive endeavour and this can prompt female adolescents to lie, cheat and steal to finance their habit (Simatwa et al., 2014). Additionally, substance abuse is associated with misconduct that disrupts the maintenance of an orderly and safe atmosphere conducive to learning among adolescents (Mothibi, 2014). Most female adolescents who abuse substances develop apathy, disruption and disrespect for others (Bakhshani, Dahmardei, Shahraki-Sanavi, Hosseinbor \& Ansari-Moghaddam, 2014). This is supported by Mokwena and Fernandes (2014), who state that most adolescents using drugs are disobedient to the elders and even to their biological parents. They transform schools into a market place for dope deals, which is associated with the disruption of school property and class disorder. Tshitangano and Tosin (2016) support the view that homes where drugs are used by these adolescents are usually sites of chaos. This is because users steal from their families and can sell anything, no matter how valuable, in order to raise some money to buy the drugs to satisfy their craving (Tulu, Shimelis \& Keskis 2015). It is clear that the aggression, lack of respect and the theft by the substance users against their families can result in a breakdown of trust and cohesion of the family unit (Bala 2017)

\section{RECOMMENDATIONS AND IMPLICATIONS FOR SOCIAL WORK}

In response to the findings revealed by this study the researchers recommend that it is critical for social workers to assist and empower especially single parents to cope with the phenomenon of nurturing children on their own. This situation should alert the government to invest more resources on proactive prevention methods of substance abuse rather than finance immensely expensive resources for rehabilitation services to the users who have developed clinical challenges. Furthermore, it is 
recommended that government consider reinforcing the school curriculum to educate about substance abuse in schools from primary level.

It is critical for the government to conduct intensive educational campaigns about drugs and involve parents and teachers, more especially in rural areas which are becoming more vulnerable to illicit drug consumption, since this tends to undermine even the efforts made to reduce HIV/AIDS. More antisubstance abuse NGOs are needed in order to mainstream awareness messages on the dangers and the ramifications of substance abuse among adolescents. It is therefore of paramount importance that governments, NGOs and the private sector work collaboratively to ensure they address the poverty of the adolescent youths.

The South African Police Service as agents of control need to deal harshly with the drug peddlers so that the supply of the drugs can be controlled. Therefore, the government should hire more substance abuse practitioners (social workers) who will strengthen education against substance abuse, especially in the rural areas. NGOs still need to be introduced, more especially in rural areas. Lastly, parents need to be educated that lenience about substance abuse among their children in pursue of happiness is in fact immoral.

\section{CONCLUSION}

It is critically important that the government along with other stakeholders fighting substance abuse synergistically and collaboratively implement the policies meant to fight substance abuse. Adequate resources such as empowering the narcotics section of the South African Police is critical. The role of the business community and the NGOs is crucial in complementing the government's effort.

\section{REFERENCES}

AROWOLO, D. 2016. The effects of western civilisation and culture on Africa. Afro Asian Journal of Social Science, 1(1), 1-14. [Online] Available: http://onlineresearchjournals.com/aajoss/art/53.pdf [Accessed: 9/09/2919].

ASANTE, O. MEYER-WEITZ, A. \& PETERSEN, I. 2014. Substance use and risky sexual behaviours among street connected children and youth in Accra, Ghana, Substance Abuse. Treatment Prevention, and Policy, 9(1):45. doi: 10.1186/1747- 597X-9-45

BABBIE, E. 2014. The basics of social research, ( $7^{\text {th }}$ ed). Australia, Brazil, Japan, Mexico, United States: Cengage Learning.

BAKHSHANI, D. DAHMARDEI, M. SHAHRAKI-SANAVI, F. HOSSEINBOR, M. \& ANSARIMOGHADDAM, A. 2014. Substance abuse among high school students in Zahedan, Health Scope, 2(4):1-5.

BALA, S. 2017. Ramifications of drug abuse among female adolescents in Mission location, Mnguma Municipality, Eastern Cape. Alice: University of Fort Hare, South Africa. (Masters thesis)

BRECHT, M. \& HERBECK, D. 2013. Methamphetamine use and violent behaviour User perception and predictors. Journal of Drug Issues, 4(43):468-482.

CHESANG, R.K. 2013. Drug abuse among the youth in Kenya, International Journal of Scientific \& Technology Research. 2(6): 126-131.

CRESWELL, J. 2014. Research design. Qualitative, quantitative, and mixed methods approaches, $\left(4^{\text {th }}\right.$ ed). United States of America: Sage Publications.

CRESWELL, J. W. \& PLANO CLARK, V. L. 2011. Designing and conducting mixed method research $\left(2^{\text {nd }}\right.$ ed $)$. Thousand Oaks, CA: Sage Publications.

DE VOS, A.C. STRYDOM, H. FOUCHÉ, C.B. \& DELPORT, C.S.L. 2005. Research at grass roots for the social sciences and human service professions. Pretoria: Van Schaik Publishers. 
GEYER, S. \& LOMBARD, A. 2014. A Content analysis of the South African National Drug Master Plan: Lessons for aligning policy with Social Development. Social Work/Maatskaplike Werk, 50 (2):329-349.

GOLIATH, V. \& PRETORIUS, B. 2016. Peer risk and protective factors in adolescence implications for drug use prevention. Social Work/MaatskaplikeWerk, 7(52):113-29.

GROENEWALD, C. ESSACK, Z. \& KHUMALO, S. 2018. Speaking through pictures: Canvassing adolescent risk behaviours in a semi-rural community in KwaZulu-Natal Province, South Africa. South African Journal of Child Health, 12(2): 57-62.

JACKSON, K. M., ROGERS, M. L., \& SARTOR, C. E. 2016. Parental divorce and initiation of alcohol use in early adolescence. Psycholy Addiction Behavior, 30(4): 450-461.

JELSMA, M. \& ARMENTA, A. 2015. The UN Drug Control Conventions, 31. [Online]. Available: https://www.tni.org/files/publication-downloads/primer_unconventions_24102015.pdf [Accessed: 31/05/2018].

KANG'ETHE, S.M. \& RHAKUDU, M. 2010. Religious education book for form 2. Gaborone, Botswana: Heinemann.

KANGE'THE, S.M. \& NOMNGCOYIYA T. 2014. Exploring selected cultures in mitigating an array of social vices in South Africa. A literature review. Mediterranean Journal of Social Sciences MCSER, 5(14).

KHESWA, J. \& MAHLALELA, V. 2014. Sexual promiscuity among African Adolescents females in Sub-Saharan countries. Mediterranean Journal of Social Sciences, 27(6):879-86.

KHUZWAYO, N. \& TAYLOR, M. 2018. Exploring the socio-ecological levels for prevention of sexual risk behaviours of the youth in uMgungundlovu District Municipality, KwaZulu-Natal. African Journal of Primary Health Care \& Family Medicine, 10(1): 2071-2928.

MAITHYA, R. OKINDA, R. \& MUNG'ATU, F. 2015. A baseline survey on effects of drug and substance abuse on academic participation among students in Technical Institutions in Kenya. International Journal of Education and Research, 3(1):629-642.

MAPONYANE, E. 2012. Undergraduate students' knowledge, attitudes, behaviours and beliefs regarding HIV and AIDS, Garankuwa: University of Limpopo (Medunsa Campus). (Masters thesis)

MAXFIELD, M. \& BABBIE, E. 2015. Research Methods for criminal justice and criminology. $\left(7^{\text {th }}\right.$ ed). United States of America: Cengage Learning.

MEADE, C. WATT, M. KIMANI, S. MACFARLANE, J. CHOIC, K. SKINNA, D. PIETERSE, D. KALICHMAN, S. \& SIKKEMAA, K. 2014. The impact of methamphetamine ("tik") on a peri-urban community in Cape Town, South Africa, International Journal of Drug Policy, 25(2):219-225.

MEADE, C.H. WATT, M.H. SIKKEMA, K.J. DENG, L.X. RANBY, K.W. SKINNER, D. PIETERSE, D. \& KALICHMAN, S.C. 2012. Methamphetamine use is associated with sexual abuse and HIV sexual risk behaviours among patrons of alcohol serving venues in Cape Town, South Africa. Journal of the International AIDS Society, 15:232-239

MOGOTSI, M. NEL, K. BASSON, W. \& TEBELE, C. 2014. Alcohol use by students at an emerging university in South Africa. Journal of Sociology, 5(2):187-195.

MOHASOA, I.P. 2010. Substance abuse among adolescents. Pretoria: University of South Africa. (Masters thesis)

MOKWENA, K. \& FERNANDES, L. 2014. Exploring the role of external locus of control in the use of Nyaope: A qualitative enquiry. PULA: Botswana Journal of African Studies, 28(1): 41-50. 
MONTGOMERY, L. \& MARINOS, D. 2016. The influence of potentially traumatic household characteristics on blunt use among Black youth, Journal of Prevention \& Intervention in the Community, 44(2):101-111. doi: 10.1080/10852352.2016.1132827

MOTHIBI, K. 2014. Substance abuse amongst high school learners in rural communities, Universal Journal of Psychology, 2(6):181-191.

MUDAVANHU, N. \& SCHENCK, R. 2014. Substance abuse amongst the youth in Grabouw Western Cape: Voices from the community, Social Work/Maatskaplike Werk, 50(3):368391.doi:10.1002/9781118320655.ch15

NADENGE, M. MUASYA, I. MUKHUNGULU, M. MWANGI, J. EWOI, L. \& GABRIEL, A. 2016. Examining the influence of drug abuse in learning institutions in Kenya. International Journal of Education and Social Science. 3(3):28-33.

NEGM, M. \& FOUAD, A. 2014. Prevalence of substance abuse among adolescent school students in Zagazig. Egyptian Journal of Psychiatry, 35(3): 161-166.

NOMNGCOYIYA, T. 2018. The impact of cultural attrition on youth behaviour: the case of Ulwaluko and Intonjane cultural practices in Mthatha and Mount Frere, Eastern Cape, South Africa. Alice: University of Fort Hare. (Masters thesis)

NWAGU, E. 2016. Alcohol and drug usage; and adolescents' sexual behaviour in Nigeria. Health Promotion International, 2(31):405-413. doi: 10.1093/heapro/dav001

NYABADZA, F. \& HOVE-MUSEKWA, S. 2010. From heroin epidemics to methamphetamine epidemics: Modelling substance abuse in a South African province. Mathematical Biosciences. US National Library of Medicine National Institutes of Health, 225(2):132-140.

OSMAN, T. VICTOR, C. ABDULMONEIM, A. MOHAMMED, H. ABDALLA, F. AHMED, A. ALI, E. \& MOHAMMED, W. 2016. Epidemiology of substance use among university students in Sudan, Journal of Addiction, 1-8. doi: 10.1155/2016/2476164

RITCHWOOD, T. FORD, H. DECOSTER, J. SUTTON, M. \& LOCHMAN, J. 2016. Risky sexual behavior and substance use among adolescents: A meta-analysis, child youth. Service Review. 52(3):74-88. doi: 10.1136/eb-2013-101593

RIMANDO, M. BRACE, A. M. NAMAGEYO-FUNA, A. PARR, T. L. SEALY, D. DAVIS, T. L. MARTINEZ, L. M. \& CHRISTIANA, R. W. 2015. Data collection challenges and recommendations for early career researchers. The Qualitative Report, 20(12):2025-2036.

RUBIN, A. \& BABBIE, E. 2015. Essential research methods for social work. $\left(4^{\text {th }} \mathrm{ed}\right)$. United States of America. Brooks/Cole Cengage Learning.

SMITH, J. \& ESTEFAN, A. 2014. Families parenting adolescents with substance abuse-recovering the mother's voice: A narrative literature review, Journal of Family Nursing. 20(4):415-441. doi: $10.1177 / 1074840714554397$

SIMATWA, E. ODHONG, S. JUMA, S. \& CHOKA, G. 2014. Substance abuse among public secondary school students: Prevalence, strategies and challenges for public secondary school managers in Kenya: A case study of Kisumu East Sub County. International Research Journal, 5(8):315-330.

TSHITANGANO, T. \& TOSIN, O. 2016. Substance use amongst secondary school students in a rural setting in South Africa: Prevalence and possible contributing factors, African Journal of Primary Health Care \& Family Medicine, 8(2):1-6.

TULU, S. SHIMELIS, K. \& KESKIS, W. 2015. Assessment of causes, prevalence and consequences of alcohol and drug abuse among Mekelle University, CSSL 2nd year students. American Journal of Applied Psychology, 3(3): 47-56. doi: 10.12691/ajap-3-3 
UNITED NATIONS OFFICE ON DRUGS AND CRIME. Annual report 2017. [Online] Available: https://www.unodc.org/wdr2017/field/Booklet_1_EXSUM.pdfMay [Accessed:17/05/2018].

VAN ZYL, A. 2013. Drug abuse amongst South African youths: Reasons and solutions. Mediterranean Journal of Social Sciences, 4(14):581-589.

WOODS-JAEGER, B.A. JAEGER JA., DONENBERG, GR. \& WILSON, H.W. 2013. The relationship between substance use and sexual health among African-American female adolescents with a history of seeking mental health services. Women's Health Issues, 23(6):e365-71. 